\title{
Entre a loucura, a incompreensão, o amor e a devoção: uma leitura de "A benfazeja", de João Guimarães Rosa
}

\author{
Tereza Paula Alves Calzolari \\ Universidade Federal do Rio de Janeiro
}

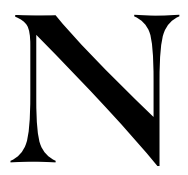

o que difere a incompreensão diante de atitudes alheias do que entendemos por loucura? Há, de fato, para a sociedade, um distanciamento entre elas? E quanto ao amor, qual o limiar entre este e o sentimento de devoção? Até que ponto é o homem capaz de se despir de seu individualismo em prol do bem estar dos que são por ele amados e da sociedade? Perguntas como estas tomaram nossas reflexões no desenrolar de contatos sucessivos com o conto "A benfazeja", do livro Primeiras estórias, de João Guimarães Rosa, cuja primeira edição, empreendida pela José Olympio, completa agora quarenta anos.

Tencionamos buscar, portanto, com esta apreciação, algumas respostas para os questionamentos apresentados acima, a partir da análise das personagens Mula-Marmela, Mumbungo e Retrupé, bem como das relações entre elas estabelecidas e as demais personagens não nomeadas do texto.

\section{Conhecendo a estória}

A estória de "A benfazeja" se passa num lugarejo, num pequeno povoado não identificado pelo narrador. É interessante sublinhar essa não localização espacial da narrativa, porque, na medida em que percorremos as linhas do texto, vamos nos aproximando da universalidade de que se vale o "causo" contado, da postura das personagens que participam da trama e da nossa mesma postura enquanto leitores chamados à reflexão sobre o que se narra. 
A personagem central do conto tem seu nome desconhecido de todos, sendo tratada tão somente por "Mula-Marmela", assim mesmo, entre aspas, na primeira vez em que aparece grafado na narrativa. Não se trata, portanto, como nos permite verificar o narrador, de seu nome registrado em cartório ou batismo, mas de uma alcunha a ela conferida pela comunidade em que vive: "Soubessem-lhe ao menos o nome. Não; pergunto e ninguém o inteira. Chamavam-na de a "Mula-Marmela", somente, a abominada."

Mas por que lhe desconhecem o nome, por que essa alcunha, a de Mula-Marmela, e por que "a abominada"? Torna-se aqui pertinente a visitação do seguinte comentário realizado pelo narrador do texto, tecido já no primeiro parágrafo do conto: "A gente não revê os que não valem a pena." E ela, de algum modo, não valia a pena, não merecia ser lembrada, era o pensamento das pessoas que também moravam no lugarejo. Marmela também Mula devido à carga pela personagem carregada, extremamente pesada, a ponto de fazê-la andar curvada, escondendo-se, comprimindose no espaço por mais amplo que este fosse. Mula-Marmela trazia nas costas, "no lombo", a sina de amar e ser amada pelo esposo, "célebre-cruel e iníquo, muito criminoso, homem de gostar do sabor de sangue, monstro de perversias", um homem que "nunca perdoou, emprestava ao diabo a alma dos outros. Matava, afligia, matava. (...) Nos tempos, e por causa dele, todos estremeciam, sem pausa de remédio". ${ }^{3}$ Amar um ser à margem, por melhor que ele fosse no trato com a esposa, já também a deixava à margem, excluída que era da e pela comunidade em que vivia.

Contudo, Marmela é pessoa-personagem desprendida de valores pessoais, próprios, procurando sempre o bem comum, de todos, o que pode explicar, de acordo com a nossa leitura da narrativa, a sua atitude extrema de matar o próprio marido, homem, como vimos, por todos temido, o "Mumbungo", também grafado entre aspas quando nos apresentado, também de nome não sabido, ignorado. A Mula, assim, aumenta a sua carga, privando-se do companheiro por amá-lo demais ao ponto de livrá-lo de sua sina de "monstro de perversias", de banido da sociedade.

\footnotetext{
${ }^{1}$ ROSA, 1998. p. 113.

${ }^{2}$ ROSA, 1998. p. 113.

${ }_{3}^{3}$ ROSA, 1998. p. 115.
} 
Sua ação, motivada pelo sentimento de devoção, de dedicação que nutre pela comunidade do pequeno lugar, não é retribuída, uma vez que também ela é excluída do convívio harmônico entre todos, por amar um homem tido como de má índole, um assassino.

Matando seu esposo, Mula-Marmela protege os que a cercam, extraindo de seu trato diário um cancro. No entanto, tomando tal atitude, o fardo da Mula cresce ainda mais em peso, pois esta sente a morte de Mumbungo, seu amor, ao mesmo tempo em que, como ele, se torna uma criminosa.

Mula-Marmela não pode ter filhos, mas Mumbungo lhe deixa um enteado, "Retrupé", também entre aspas grafado, um alguém que, como ela e seu companheiro, não valia a pena ser revisto, igualmente marginalizado em cadeia, apenas por ser filho de quem era. Retrupé também arrasta um fardo e, do mesmo modo que o pai, quiçá por vingança à exclusão de ambos e da morte do progenitor, curte a sede de sangue, a sede mais profunda que guarda, mascarada por desejos de bebidas alcoólicas:

Porque, ele mesmo, não sabendo que não havia de beber, o que não fosse - ah, se! - o sangue das pessoas. Porque sua sede e embriaguez eram fatais, medonhas outras, para lá do ponto. (...) é o filho tal-paital; o "cão", também na prática verdade. ${ }^{4}$

Uma vez mais a personagem central intervém na ordem natural das coisas. Ela cega o enteado, privando-o ou ao menos dificultando-o na concretização de seus intentos. Retrupé, o cego, o de passos para trás, num retrocesso de pagar pela moira paterna, empurrado para longe de seu desejo, de sua sina, pela madrasta, a Mula, que também dizem ter sido a responsável por sua morte:

Não viram, na madrugada, quando ele lançou o último mau suspiro. Sim, mas o que vocês crêem saber, isto seriamente afirmam; que ela, a MulaMarmela, no decorrer das trevas, foi quem esganou estranguladamente o pobre diabo, que parou de se sofrer, pelos pescoços; no cujo, no corpo defunto, após, se viram marcas de suas unhas e dedos, craváveis. Só não a acusaram e prenderam, porque maior era o alívio de a ver partir, para nunca, $(\ldots)^{5}$

${ }^{4}$ ROSA, 1998. p. $115-116$.

${ }^{5}$ ROSA, 1998. p. 121. 
Mula-Marmela, agora, ainda mais sobrecarregada em sua carga, por amor ao enteado ("Se não o matasse, ele se teria condenado ainda mais?"6) e dedicação aos seus semelhantes. Mas, e a recíproca se confere, a comunidade retribui à personagem tamanha devoção? Como vimos, a resposta a esta pergunta é negativa; e o narrador, consciente das dores de Marmela, do peso de suas escolhas, toma a sua defesa ao mesmo tempo em que nos acusa, personagens e leitores, de negligenciá-la, de marginalizá-la, de nem ao menos lhe agradecer por sua dedicação, por seus atos despidos de interesses particulares, visando ao bem de todos.

Antes, porém, de adentrarmos em maiores reflexões acerca da postura do narrador de "A benfazeja", bem como de outros tópicos de igual relevância mediante a nossa leitura do texto, cumpre-nos lembrar como a narrativa termina, uma vez que o nosso principal objetivo, neste momento, é o de apresentar um contato primeiro, uma apreciação inicial da estória em questão: Mula-Marmela parte, sem de ninguém se despedir, até porque não tinha de quem fazê-lo, tomando nas costas um cachorro morto, abandonado e já meio podre, encontrado no caminho:

(...) pegou-o às costas, o foi levando -: se para livrar o logradouro e lugar de sua pestilência perigosa, se para piedade de dar-lhe cova em terra, se para com ele ter com quem ou quê se abraçar, na hora de sua grande morte solitária? Pensem, meditem nela, entanto. ${ }^{7}$

\section{Buscando compreender "Mumbungo" e "Retrupé", bem como a relação entre ambos e "Mula-Marmela"}

Acreditamos que já tenha ficado claro, dentro dos limites que nos impõe a narrativa, o caráter da personagem Mumbungo, bem como o temor justificado que por ela sentem os moradores do lugarejo. Vimos também como o seu comportamento gera, em conseqüência do medo sentido pelas demais personagens, a sua exclusão do convívio comum. E como, ainda, em cadeia, sua esposa e filho são marginalizados, um círculo vicioso.

\footnotetext{
${ }^{6}$ ROSA, 1998. p. 119.

${ }^{7}$ ROSA, 1998. p. 122.
} 
O que, no entanto, não abordamos e passamos agora a fazer é o temor sentido pelo próprio Mumbungo, o temor de Mula-Marmela:

O Mumbungo queria à sua mulher, a Mula-Marmela, e, contudo, incertamente, ela o amedrontava. Do temor que não se sabe. Talvez pressentisse que só ela seria capaz de destruí-lo, de cortar, com um ato de "não", sua existência doidamente celerada. Talvez adivinhasse que em suas mãos, dela, estivesse já decretado e pronto o seu fim. Queria-lhe e temia-a - de um temor igual ao que agora incessante sente o cego Retrupé. Soubessem, porém, nem de nada. A gente é portador. ${ }^{8}$

Como pode Mumbungo temer a própria e amada esposa? Como pressentir o corte, por ela, do fio de sua existência? Mula-Marmela, de fato, assume o papel da parca Láquesis, irmã de Cloto e Átropo, também parcas ou meras. De acordo com a mitologia greco-romana, as três irmãs regulavam a duração e a qualidade da vida dos mortais, do momento de seu nascimento até a morte, por meio de um fio. Átropo fiava, Cloto enrolava este mesmo fio e, por fim, Láquesis o cortava, impondo um término à extensão da vida do homem a quem correspondia aquele determinado fio. O mesmo faz a protagonista de "A benfazeja", decretando o fim da existência do próprio marido e do enteado. Mas, retornando e ampliando a pergunta que fazíamos, como Mumbungo e Retrupé podem pressentir tal acontecimento? A resposta, ainda que subjetiva, encontra-se no próprio tecido do texto, no que diz respeito, sobretudo, ao enteado.

Este, apesar de grande e forte, como nos é apresentado pelo narrador, deixa-se guiar pela madrasta, por motivo de sua cegueira, nas andanças pelo lugarejo.

(...) ela o guia apenas com sua dianteira presença, ele segue-a pelo jeito, pelo se deslocar do ar - como em transvôo se vão os pássaros; ou o que ele percebe à sua frente é a essência vivaz da mulher, sua sombra-da-alma, fareja-lhe o odor, o lobum??

Retrupé não se apoia no braço de Marmela, como é o comportamento natural das pessoas privadas do sentido da visão. Ele apenas e tão somente a segue, seja pelo deslocamento do ar, seja por sua forte presença. Mas o fato é que sua guia também o protege. Se seu chapéu cai, ela o recupera

\footnotetext{
${ }^{8}$ ROSA, 1998. p. 115.

${ }^{9}$ ROSA, 1998. p. 117.
} 
e limpa para devolvê-lo. Chapéu esse que Retrupé nunca tira por não respeitar ninguém. O enteado de Mula-Marmela exige esmolas da população em altos brados, como se essa fosse uma obrigação das pessoas da comunidade para com ele, o pagamento de uma dívida, de uma rejeição. Mas se a madrasta o interpela, o que é feito por um murmúrio ou meia-palavra, ele logo perde o equilíbrio, a postura altiva, tornando-se fraco e trêmulo.

Em nossa leitura, o comportamento de Mumbungo e Retrupé diante de Marmela pode ser explicado pela consciência do amor e dos cuidados que dela partem em sua direção. O que seria de suas vidas sem esse sentimento, sem essa doação da personagem? Rejeitados por todos, eles encontram em Mula-Marmela o carinho e o apoio indispensáveis para a sua existência. Carinho e apoio que a tornam um ser extremamente necessário, essencial, quase divino. A personagem tem, portanto, em suas mãos o controle da vida de ambos, o que se verifica, como vimos, no decorrer da estória.

Quanto ao comportamento de Mumbungo, o texto não nos fornece pistas suficientes para que possamos investigá-lo, desvendá-lo em sua totalidade. Não conhecemos a sua "história", não sabemos, portanto, o que poderia movê-lo a atitudes tão violentas, a tal desejo de sofrimento e sangue alheios. Podemos sim supor um círculo vicioso, na medida em que ele mata e é rejeitado pela comunidade e, enraivecido, torna a matar e a fazer sofrer. "E, no entanto, com a mulher, davam-se bem, amavam-se. Como? O amor é a vaga, indecisa palavra." ${ }^{10} \mathrm{O}$ bom relacionamento mantido por Mumbungo com a esposa, à parte o medo que dela sente, nos faz refletir a cerca de sua sina de "monstro de perversias". Conforme nos diz Riobaldo, em Grande sertão: veredas:

Que o que gasta, vai gastando o diabo de dentro da gente, aos pouquinhos, é o razoável sofrer. E a alegria de amor - compadre meu Quelemém diz. Família? Deveras? É, e não é. O senhor ache e não ache. Tudo é e não é... Quase todo mais grave criminoso feroz, sempre é muito bom marido, bom filho, bom pai, e é bom amigo-de-seus-amigos! ${ }^{11}$

No que se refere a Retrupé, por outro lado, cremos realmente, conforme já foi apontado, num desejo de vingança da exclusão pela

\footnotetext{
${ }^{10}$ ROSA, 1998. p. 115.

${ }^{11}$ ROSA, 1976. p. 12.
} 
sociedade, exclusão sua, de seu pai e sua madrasta. Desejos de vingança pela morte do pai e por sua cegueira, objeto de uma atitude que não sua, que não de nascença. Da "história" do cego Retrupé, diferentemente, o narrador nos dá a conhecer parte significativa.

Cabe aqui ainda assinalar o modo como este conduz a narrativa: a crítica tecida ao comportamento das personagens e ao nosso próprio diante de "Mumbungo", "Retrupé" e, sobretudo, de "Mula-Marmela"; o que nos dá ou não a conhecer destas personagens e da estória por ele contada. Conforme o próprio sublinha: "Sou de fora." ${ }^{12}$ e é justamente essa condição de estrangeiro que lhe permite um novo olhar, um olhar diverso, crítico, do que a ele é dito, do que ele vê. Um olhar distanciado, sem os vícios daqueles que quotidianamente vivenciam de dentro dada situação. Daí suas indagações, reflexões a nós tão incômodas e simultaneamente necessárias.

\section{3. "Mula-Marmela" e o(s) sentimentos(s) que a move(m)}

Mula-Marmela, como vimos, aumenta o seu fardo por opção própria: escolhe viver com um homem marginalizado pela sociedade, tornando-se igualmente marginalizada; mata-o, tornando-se como ele uma assassina e sentindo a sua dolorosa ausência; passa a cuidar do enteado, cega-o e, por fim, também o mata; partindo, enfim, para um outro e desconhecido lugar, solitariamente. Quais sentimentos e/ou valores movem a personagem a tais atitudes? O que faz com que ela opte pelo bem estar dos outros em detrimento do seu próprio bem estar? Tentaremos, agora, buscar também essas respostas, como já partimos à procura de outras, nas próximas páginas, a fim de uma compreensão um pouco mais elaborada do texto.

De acordo com a nossa leitura, os motivos que levam a personagem a tais benfeitorias, o que confere, inclusive, o epíteto de "A benfazeja" à narrativa, podem ser buscados nas idéias morais e políticas romanas, raiz da cultura ocidental.

No contato com os valores da cultura clássica, dois deles nos chamam de imediato a atenção, a saber, as idéias de fides e pietas. A distinção entre ambas, apesar de tênue, nos conduz a uma reflexão assaz pertinente para algumas das respostas que procuramos.

12 ROSA, 1998. p. 115. 
O sentimento da fides, para Maria Helena da Rocha Pereira, encontra-se "no centro da ordem política, social e jurídica de Roma."13 Ainda segundo ela, o valor original da palavra estaria associado à idéia de garantia. Tratar-se-ia de um pacto, de uma espécie de juramento que comprometeria igualmente as partes envolvidas.

A estudiosa ainda coloca que parte da capacidade de congregação de povos diversos por Roma tem na fides uma de suas explicações. Com o intuito de exemplificar tal afirmação e de tornar mais claro esse conceito, duas histórias nos são contadas, uma das quais passamos agora a transcrever:

(...) em Tito Lívio V. 27, onde se conta um episódio da luta com os Faliscos: o professor que leva os alunos para longe da escola, a fim de traiçoeiramente os entregar a Camilo; o general romano que lhe responde que não são essas as armas de que se servem; e a população entusiasmada com o procedimento leal, e que logo pede a paz. E o historiador continua: "a fides romana, a justiça do general são celebrados no Forum e na Cúria."E, no começo do capítulo seguinte, confirma que Camilo entrara na Urbe com uma glória maior que a do triunfo, "por ter vencido os inimigos pela justiça e pela fides."O episódio trata do século IV a.C. ${ }^{14}$

Com relação à pietas, ela se define como um sentimento de devoção, de lealdade "para com aqueles a quem o homem está ligado por natureza (pais, filhos, parentes)". ${ }^{15}$ Entendida como um vínculo afetivo natural e obrigatório entre as partes que compõem uma família, a pietas, segundo Ronald Syme, citado por Maria Helena da Rocha Pereira, em determinadas situações, dava margem, impunha, por assim dizer, vinganças das mais cruéis.

Uma vez conceituados os dois valores, nos consideramos mais próximos de uma explicação para as atitudes da protagonista do conto apreciado, bem como de Retrupé em sua vingança desenfreada. Podemos compreender as opções da primeira como oriundas de um sentimento seja de pacto seja de obrigação, mas, enfim, de lealdade para com aqueles que a cercam.

\footnotetext{
13 PEREIRA, 1990. p. 322.

${ }^{14}$ PEREIRA, 1990. p. 326.

15 PEREIRA, 1990. p. 328.
} 
O marido é o primeiro a ser expurgado da triste sina de excluído da comunidade. Em seguida, se entendermos a morte de Retrupé como homicídio cometido pela madrasta, raciocínio ao qual somos conduzidos pelo discurso do narrador, o enteado também é libertado do jugo alheio por meio de um ato de devoção, quiçá oriundo do sentimento de pietas da parte de quem dele cuida, seu único "ente" próximo, sua conexão mais íntima e, até certo ponto, segura com o mundo.

O mesmo pode ser dito com relação aos demais habitantes do lugarejo no qual se passa a estória. Pondo-se um ponto final à existência material de Mumbungo e Retrupé, também a comunidade estaria livre dos temores de morte e dos muitos perigos pressentidos. A ela, Mula-Marmela, caberia o papel, a sina de zelar pelo bem estar de todos, ainda que para tanto sua solidão se fizesse necessária.

Ao partir do espaço no qual até então residia, como já tivemos a oportunidade de assinalar, a personagem se depara com um cão morto na estrada. Ela o toma nos braços e dele faz seu companheiro de jornada,

se para livrar o logradouro e lugar de sua pestilência perigosa, se para piedade de dar-lhe cova em terra, se para com ele ter com quem ou quê se abraçar, na hora de sua grande morte solitária? ${ }^{16}$

Cremos na verossimilhança dessas diferentes possibilidades. A escolhida por Marmela, de fato, pouco nos importa, uma vez que em nada esgota a complexidade e riqueza de suas ações e, por conseguinte, do texto.

\section{No limiar entre a loucura e a incompreensão}

Martin Buber, filósofo existencialista, buscara compreender a relação entre os homens a partir de duas palavras-princípio, isto é, a partir de dois modos de ser no mundo: a compreensão do outro como Tu ou como Isso. No primeiro caso, estamos diante de uma relação dialogal essencial para os "atos" de ser e estar no mundo; o Tu é percebido pelo Eu como parceiro, compreendido, destarte, em sua alteridade. Em contrapartida, na relação Eu-Isso, o outro é deslocado pelo Eu da condição de Tu para Isso, porque compreendido como veículo de experiência ou

${ }^{16}$ ROSA, 1998. p. 122. 
uso, como objeto manipulável, não como um fim mas um meio, negando, portanto, ao outro a sua alteridade.

A relação Eu-Isso não deve ser compreendida, ainda segundo Buber, como negativa em todas as suas expressões. Trata-se de um relacionamento essencial na vida do ser-humano, na medida em que não constitua a única atitude com relação ao outro, que seja o único interesse que o mova e direcione os valores de sua existência ou, nas palavras do próprio filósofo, "Se o homem não pode viver sem o Isso, não se pode esquecer que aquele que vive só com o Isso não é homem." ${ }^{17}$

A leitura do outro como meio, como veículo para se atingir algo, encontra-se intimamente atrelada à idéia do querer apenas para si e do não compartilhar. Ora, se somos, enquanto homens, constituídos de relações, negar ao outro o caráter de ser e tratá-lo como objeto elimina por completo o que se pode considerar como convívio ou vida em sociedade.

Esse é o tratamento dispensado à Mula-Marmela, Mumbungo e Retrupé pela comunidade em que vivem. Se chamamos aqui o Existencialismo à baila, é com o intuito de melhor compreender o tipo de relação dessas personagens com os moradores do local, ou melhor, a antirelação partida desses moradores em direção a tríade marginalizada.

Havia algo em Mula-Marmela, a benfazeja, que fazia com que não valesse a pena pensá-la. No que não se observou, nem indagou, "a muita coisa" (p.113), como nos coloca o narrador. Talvez melhor fosse forjar a inexistência de um alguém que não coubesse nas normas pré-estabelecidas pela sociedade, de um alguém que representasse uma ameaça para essas mesmas normas, do que buscar entendê-la e aceitá-la em sua alteridade. Uma mulher capaz de passar por sobre os próprios desejos e bem-estar, supernutrida do sentimento de devoção pelos que a cercam e que, de fato, não se importam com isso ou com ela; um assassino e um indivíduo impulsionado pela vontade descontrolada de vingança devido à morte do pai e sua marginalização.

Detenhamo-nos por um breve momento nesta última personagem. Retrupé não pede esmolas, as exige ... e as consegue sem maiores dificuldades. Observemos:

O cego pedia suas esmolas rudemente. Xingava, arrogava, desensofrido, dando com o bordão nas portas das casas, no balcão das vendas.

${ }^{17}$ BUBER, [s.d.]. p. LIV. 
Respeitavam-no, mesmo por isso, jamais se viu que o desatendessem, ou censurassem ou ralhassem, repondo-o em seu nada. Piedade? Escrúpulo? Mais seria como se percebessem nele, de obscuro, um mando de alma, qualidade de poder. ${ }^{18}$

Como explicar as atitudes de Retrupé e da comunidade com relação às esmolas? Se ele as pede desse modo tão visceral e ao mesmo tempo sofrido e as tem é porque, concernente a nossa leitura, a elas tem direito, e os demais têm o dever de dá-las. "Piedade? Escrúpulo?", "Respeitavam-no"? Se não o respeitavam enquanto homem, em sua alteridade, faziam-no na forma de esmolas, como penitência. Há uma dívida entre os habitantes do lugarejo em que se passa a estória e o cego Retrupé. Negam-lhe a posição de $T u$, o direito de ser humano, de exercer, sem recalques, a sua existência. Tal personagem é anulada em suas condições mais básicas enquanto indivíduo por todos que o rodeiam. Estigmatizado pela comunidade por ser filho de um assassino, cegado pela enteada, "poupado" pela mesma de sua amarga existência. Só lhe resta como forma de atrair para si atenção, de gritar pela sua condição de homem, por meio do incômodo causado aos outros, dos brados com os quais exige esmolas, dos mulambos de suas vestes. Seu chapéu "chato, nem branco nem preto" ${ }^{19}$ nunca abandonado, e restituído, quando em queda, pela enteada, é também tentativa de resgate de sua humanidade.

Chevalier e Gheerbrant, no Dicionário de Símbolos, apresentam o chapéu como sinal de superioridade, de identificação. Correspondente à coroa, representa poder, soberania, e ainda, no francês coloquial, "porter le chapeu" significa "assumir uma responsabilidade, mesmo por uma ação que não se tenha cometido": ${ }^{20}$ "Mais seria como se percebessem nele, de obscuro, um mando de alma, qualidade de poder."

Os pés, ainda segundo o mesmo dicionário, também simbolizam poder, deixando as marcas das pegadas do homem "sobre as veredas boas ou más - que ele escolhe, em função de seu livre arbítrio. Inversamente, o pé leva a marca do caminho - bom ou mau - percorrido."21 Conforme

\footnotetext{
${ }^{18}$ ROSA, 1998. p. 114.

${ }^{19}$ ROSA, 1998. p. 116.

${ }^{20}$ CHEVALIER \& GHEERBRANT, 1999. p. 232.

${ }^{21}$ CHEVALIER \& GHEERBRANT, 1999. p. 695.
} 
tivemos a oportunidade de verificar, a personagem não usufrui, de fato, do livre arbítrio que lhe seria de direito, portanto, Retrupé, por toda a sua caminhada, de passos para trás, "o Retrupé, sem adiante."22

Por fim, quanto ao sentido da visão, do qual a personagem é pela madrasta privado, destacamos de Chevalier \& Gheerbrant a seguinte passagem:

O olhar é carregado de todas as paixões da alma e dotado de um poder mágico, que lhe confere uma terrível eficácia. O olhar é o instrumento das ordens interiores: ele mata, fascina, fulmina, seduz, assim como exprime. $^{23}$

Cegando o enteado, portanto, Mula-Marmela o estaria, de fato, afastando da concretização de seus desejos de sangue, de vingança, ou ao menos buscando deixar menos aparentes os seus objetivos, uma vez que pelo olhar, segundo o fragmento acima transcrito, o homem permitiria a leitura de suas "ordens interiores", seu(s) "mando(s) de alma", e os de Retrupé eram inadmissíveis pela e para a sociedade.

Ele precisava de matar, para a fundo se cumprir, desafogado e bem. Mas, não pode. Porque é cego, apenas. O cego Retrupé, sedicioso, então, insulta, brada espumas, ruge - nas gargantas do cão. Sabe que é de outra raça, que vem do ainda horroroso, informe; que ainda não entendeu a mansidão, pelo temor? Então, o cego Retrupé esbarra com o impoder da cegueira; agora ele não poderá alcançar ninguém, se a raiva mais o cega; pode? O cego Retrupé cochicha consigo - ele ofende o invisível. Para ele, graças à cegueira, este nosso mundo já é algum além. E se assim não fosse? Alguém seria capaz de querer ir pôr o açamo no cão em dana? ${ }^{24}$

E de Retrupé, assim como de Mumbungo e Mula-Marmela, se dizia muita inverdade, se falava a muita falsa coisa, segundo o narrador. Contavase, por exemplo, que o dinheiro arrecadado com as esmolas ficava apenas para a madrasta, que Retrupé bebia, o que não podia ser já que MulaMarmela o impedia. Enfim, mais fácil declarar mentiras, construir verdades queridas do que procurar compreender as atitudes do outro. Atitudes que,

\footnotetext{
${ }^{22}$ ROSA, 1988. p. 114.

${ }^{23}$ CHEVALIER \& GHEERBRANT, 1999. p. 653.

${ }^{24}$ ROSA, 1998. p. 119.
} 
conforme já tivemos a oportunidade de assinalar, representavam um grande perigo para as normas pré-estabelecidas pela sociedade, ainda mais em se tratando de um pequeno povoado como o da estória.

Afirmavam ser Mumbungo "maltratado do miolo". ${ }^{25} \mathrm{E}$ a mesma atitude se repetia com relação às demais personagens marginalizadas. Agora já se torna mais fácil a resposta para o questionamento que buscamos levantar, quando nomeamos este fragmento de nossa apreciação como No limiar entre a loucura e a incompreensão.

Os "loucos", os homens considerados como fora dos padrões da normalidade pela sociedade ou os seres de exceção, seja lá qual for a alcunha ou a vereda adotada, já nos mostra a História terem sido por muito tempo, como são até hoje, banidos do convívio comum com as pessoas ditas "normais", "sãs". Num primeiro momento isolados em cárceres, os mesmos utilizados para os doentes de lepra e doenças venéreas, para, em seguida, serem enviados em embarcações para onde a vista não alcançasse. A literatura já retratara o caso na Idade Média, com Tristão e Isolda, por exemplo, e no período da Renascença com a Narrenschiff ou a Nau dos Loucos, retomando-o inúmeras outras vezes.

Mas de todas essas naves romanescas ou satíricas, a Narrenschiff é a única que teve existência real, pois eles existiram, esses barcos que levavam sua carga insana de uma cidade para outra. Os loucos tinham então uma existência facilmente errante. As cidades escorraçavam-nos de seus muros; deixava-se que corressem pelos campos distantes, quando não eram confiados a grupos de mercadores e peregrinos. ${ }^{26}$

Antes de abandonarmos nosso breve diálogo com Foucault, vale lembrar a passagem em que a "loucura" é por ele apontada como algo que lembra irremediavelmente a cada um a sua verdade. Por que então deixá-la visível, permitir que a "loucura" se esbarre conosco pelas ruas, lembrandonos a todo instante o medo que temos do desconhecido, da morte, de tudo aquilo sobre o qual não temos domínio? Afastemos, então, de nós a "loucura", para que ela não mais nos incomode. Essa, a solução aparentemente mais fácil, mais simples. Esse, o meio utilizado pelos moradores do lugar em que

${ }^{25}$ ROSA, 1998. p. 115.

${ }^{25}$ FOUCAULT, 2000. p. 9. 
se passa a estória de "A benfazeja”, a exclusão, a marginalização. Expulsar da cidade Mula-Marmela? Era de todos o desejo, mas nem foi preciso uma atitude desnudada de farsas, mais direta, para que tal acontecesse. Ela mesma, como vimos, extirpou dois cancros, Mumbungo e Retrupé, com suas próprias mãos, para depois partir para não se sabe onde, solitariamente. A porta já se encontrava aberta, bastando, pois e tão somente, atravessá-la.

\section{Conclusão}

O narrador de "A benfazeja", acusando, repreendendo as personagens da própria estória por ele contada e a nós, leitores, por nossa desatenção e conseqüente incompreensão com relação à protagonista da narrativa, Mula-Marmela, constituiu a nossa primeira motivação para a apreciação do conto supracitado. Postura tão diferente das dos demais narradores de Rosa não nos passou desapercebida. $O$ fato de a cada instante sermos condenados por uma atitude de toda a vida, o desinteresse pelo outro e a sua redução a isso, pareceu-nos um alerta. A insistência em tal postura causou-nos desconforto e nos impulsionou para a análise que agora finalizamos.

Certamente não pretendemos, aqui, proporcionar uma leitura final, uma leitura pronta para a narrativa. Longe disso, acreditamos e esperamos tão somente haver alcançado o nosso objetivo de ler o conto, refletindo acerca de aspectos por nós considerados fulcrais para a sua interpretação. Esperamos que este nosso breve percurso possa servir de auxílio à outras e sempre bem-vindas leituras de suas narrativas.

\section{Referências Bibliográficas}

BUBER, Martin. Eu e tu. São Paulo: Moraes, [s.d.].

CHEVALIER, Jean \& GHEERBRANT, Alain. Dicionário de símbolos. 13. ed. Rio de Janeiro: José Olympio, 1999.

FOUCAULT, Michel. História da loucura. São Paulo: Perspectiva, 2000.

GRIMAL, Pierre. Dicionário da mitologia grega e romana. 3. ed. Rio de Janeiro: Bertrand Brasil, 1997.

PAZ, Octavio. A dupla chama amor e erotismo. 3. ed. São Paulo: Siciliano, 1994. 
PEREIRA, Maria Helena da Rocha. Estudos de história da cultura clássica. 2. ed. Lisboa: Fundação Calouste Gulbenkian, 1990. v. II

ROSA, João Guimarães. A benfazeja. In: Primeiras estórias. Rio de Janeiro: Nova Fronteira, 1998.

Grande Sertão: Veredas. 11. ed. Rio de Janeiro: José Olympio, 1976.

\section{Resumo}

Qual a distância entre a incompreensão diante de atitudes alheias do que entendemos por loucura? Até que ponto é o homem capaz de se despir de seu individualismo em prol do bem estar dos que são por ele amados e da sociedade? Perguntas como estas tomaram nossas reflexões no desenrolar de contatos sucessivos com o conto "A benfazeja", do livro Primeiras estórias, de João Guimarães Rosa, cuja primeira edição, empreendida pela José Olympio, completa agora quarenta anos.

Tencionamos buscar, portanto, com esta apreciação, algumas respostas para os questionamentos apresentados acima, a partir da análise das personagens Mula-Marmela, Mumbungo e Retrupé, bem como das relações entre elas estabelecidas e as demais personagens não nomeadas do texto.

\section{Abstract}

What is the distance between the inability to understand people's attitudes and what we consider madness? How far does the human capacity to let go his individualism to benefit the ones he loves and the society? Questions like these led us to reflections through several contacts with the story "A benfazeja", from the book "Primeiras estórias", by João Guimarães Rosa, whose first edition, engaged in by José Olympio, celebrates now its fortieth anniversary.

Therefore, we intend to look for some answers to the questions above through the analisys of the characters: Mula-Marmela, Mumbungo and Retrupé, as well as relationships established among them and the other not named characters in the text. 